\title{
Е. Вивич
}

ORCID: 0000-0003-2681-4216

Da.jurandi.veniam@gmail.com

Национальньй исследовательский университет

"Высшая школа эконолики"

(Россия, Москва)

\section{«УБЕЙТЕ ВРЕМЯ С ПОЛЬЗОЙ»: ТРАНСФОРМАЦИЯ КРОССВОРДА ПОСЛЕ ПЕРЕСТРОЙКИ}

\begin{abstract}
Аннотация. Будучи одним из характерных феноменов постсоветского культурного мира, кроссворд пока мало привлекает внимание исследователей. В статье предпринята попытка показать эвристический потенциал кроссворда как материала для изучения постсоветского общества. Отталкиваясь от интерпретации, предложенной в статьях Ольги Шевченко, автор предлагает акцентировать значение исследований традиционной культуры и когнитивной психологии для понимания природы кроссворда как культурного френомена. Шевченко фиксирует всплеск потребления кроссвордов в России в 1990-2000-е годы, объясняя его особой значимостью головоломки с интеллектуальным ореолом для постсоветской интеллигенции. В данной статье предлагается альтернативный взгляд на кроссворд. Описанные в статье изменения объясняются тем, что кроссворд встраивается в социокультурный контекст наравне с явлениями фольклора, начиная исполнять подобные им функции. Появившись как агент передачи некритически принимаемого, «энциклопедического» знания, кроссворд посредством изменения и упрощения текстового содержимого начинает выступать в роли транслятора повседневного опыта, а также нормативных и ценностных установок сообщества, внутри которого он появляется. Выводы доказываются посредством обращения к результатам исследований в рамках других дисциплин.
\end{abstract}

Ключевые слова: кроссворды, игры, головоломки, загадки, метафроры, перестройка, кроссвордный бум, повседневность

Благодарности. Статья подготовлена в ходе проведения исследования по проекту НУГ № 17-05-0003 в рамках Программы «Научный фонд Национального исследовательского университета "Высшая школа экономики” (НИУ ВШЭ)» в 2018 г. и в рамках государственной поддержки ведущих университетов Российской Федерации «5-100».

Хотелось бы выразить огромную благодарность своему научному руководителю Б. Е. Степанову, а также Н. В. Самутиной за неоценимую помощь в редактуре и составлении статьи. 
Для иитирования: Вивич E. «Убейте время с пользой»: трансформация кроссворда после перестройки // Шаги/Steps. Т. 5. № 4. 2019. С. 239-259. DOI: 10.22394/2412-9410-2019-5-4-239-259.

Статья поступила в редакиию 1 октября 2018 г.

Принято к печати 22 июня 2019 г.

Shagi / Steps. Vol. 5. No. 4. 2019

Articles

E. Vivich

ORCID: 0000-0003-2681-4216

Da.jurandi.veniam@gmail.com

National Research University Higher School of Economics

(Russia, Moscow)

\title{
"KILL TIME PRODUCTIVELY": THE TRANSFORMATION OF CROSSWORD PUZZLES After Perestroika
}

\begin{abstract}
The crossword, one of the notable phenomena of post-Soviet Russian culture, still remains largerly unnoticed by researchers. In this paper, we attempt to show the heuristic potential of the crossword as material for study of post-Soviet society. Proceeding from an interpretation offered by O. Shevchenko in his articles, the author proposes emphasizing the significance of studies in traditional culture and cognitive psychology when seeking to understand the nature of the crossword as a specific cultural phenomenon.

Shevchenko has noted an increase in the consumption of crosswords in the 1990-2000s. She explains it by noting the special significance of puzzles to which an intellectual aura attached for the post-Soviet intelligentsia. In this paper an alternative view of crosswords is proposed. The crossword not only became more popular, but also was simplified. The transformed form became incorporated into the social and cultural context alongside phenomena of folklore. The crossword literally starts to perform functions similar to those carried out by riddles. Having appeared as an agent of transmission of uncritically accepted, "encyclopedic" knowledge, the crossword becomes a medium of transmission of everyday experience; it also naturally reflects and translates the norms and values of the community in which it appears. The author supports her conclusions by utilizing the results of research in other fields, that in one way or another are connected with crosswords.
\end{abstract}

Keywords: crosswords, games, puzzles, riddles, metaphors, Perestroika, the crossword boom, everyday life 
Acknowledgements. This paper was prepared as part of the project of the academic research group № 17-05-0003 within the scope of the "HSE Academic Fund Programme" in 2018 and within the scope of government support of the leading universities of Russian Federation " 5 -100".

I am very grateful to my scientific supervisor B. E. Stepanov, who put so much effort in supporting this study and encouraged me never to give up. I also want to thank the wonderful N. V. Samutina for help in editing and composing the article.

To cite this article: Vivich, E. (2019). "Kill time productively": The transformation of crossword puzzles after Perestroika. Shagi/Steps, 5(4), 239-259. (In Russian). DOI: 10.22394/2412-9410-2019-5-4-239-259.

Received October 1, 2018

Accepted June 22, 2019

$\mathrm{B}$ условиях отсутствия интереса к исследованию кроссвордов исключение составляет работа Ольги Шевченко, посвященная анализу кроссворда в постсоветской культуре [Shevchenko 2007]. В этой работе отмечаются важные тенденции, связанные с трансформацией, которую претерпевает кроссворд при переходе от советского к постсоветскому обществу. Шевченко предлагает рассматривать решение кроссвордов как занятие, позволявшее бывшей советской интеллигенции компенсировать потерю статуса интеллектуального меньшинства: кроссворды позволяли найти применение узкоспециальным знаниям, ставшим бесполезными в условиях, когда в силу экономической ситуации многим пришлось менять профессию и работать не по специальности. Вместе с тем предлагаемая исследовательницей интерпретация этого процесса представляется не вполне убедительной. В частности, это касается тезиса о компенсаторном значении кроссворда для постсоветской интеллигенции. С нашей точки зрения, этот тезис скорее противоречит фиксируемым в статье изменениям, которые произошли в постсоветский период. Залогом адекватной интерпретации кроссворда является, на наш взгляд, существенная ревизия представления о нем как интеллектуальном развлечении. Для того чтобы наглядно продемонстрировать это, мы, с одной стороны, попытаемся дать характеристику трансформации кроссворда в постсоветский период, обратившись к пособиям по составлению кроссворда. С другой стороны, нам представляется важным указать на более рутинный режим функционирования кроссвордов, опираясь на их исследования в когнитивной психологии, и наметить возможные параллели между кроссвордами и феноменами традиционной культуры.

\section{1}

Классический вариант кроссворда представляет собой соединение симметричной формы, составленной из клеток (кроссвордной фигуры), и текстового содержания, часть которого записана рядом с фигурой, а часть зашифрована и должна быть вписана решающим. Головоломки, выглядевшие как квадраты из клеток, которые следовало заполнить пересекающимися словами, публиковались на протяжении всего XIX в. Однако историю современного кроссворда 
принято отсчитывать от 1913 г., когда в газете «The New York World» была опубликована головоломка, составленная Артуром Вайном. Кроссворд Вайна был радиально симметричен: слова в нем располагались по кругу, определения были очень краткими, до четырех слов. Он стал на долгое время образцом классического кроссворда, для которого было важно следование правилам, обеспечивавшее четкое воспроизведение формы и задач головоломки. После головоломки Вайна кроссворды стали популярны вначале в Америке, а затем и в Европе, и уже в 1920-е годы распространялись в огромных количествах.

В СССР первый кроссворд, как считается, был напечатан в журнале «Огонек» в 1929 г. Несмотря на идеологическую нагруженность советского кроссворда, по форме и содержанию он поначалу не отличался от западного варианта. К 1940-м годам кроссворды стали обязательным компонентом последней страницы практически любой советской газеты. Советский кроссворд был призван «научить», а не только развлечь, и преподносился как средство развития интеллекта и повышения уровня «культурности» [Shevchenko 2007: 579]. Высокий статус кроссворда предполагал тщательность в разработке кроссвордной сетки и логическую выверенность в формулировке вопросов, а решение этой головоломки требовало определенной эрудиции ([Пискунов 2000; Connor 2014; McKie 2013; Shevchenko 2007] и др.).

После распада Советского Союза отмечается трансформация как формы кроссворда, так и его содержания [Shevchenko 2007]. Ее причины не совсем однозначны, но, вероятно, именно произошедшие изменения приводят к скачку популярности кроссвордной продукции на рубеже 1990-х и 2000-х годов. В прошлом размещавшиеся на последних страницах газет, кроссворды выделяются в самостоятельный кластер журнальной продукции, появляется своего рода специализированная индустрия кроссвордов [Ibid.: 583]. Если прежде они подавались как средство развития интеллекта с предложением «пораскинуть извилинами», то после перестройки превратились в ненавязчивое развлечение, с которым можно скоротать время. Кроссворды в облегченной форме систематически появляются в самых расхожих изданиях (таких как «Лиза» или «Отдохни!»), а также в специальных сборниках, которые печатаются на тонкой некачественной бумаге и имеют огромные тиражи. Эти сборники всегда можно было приобрести в киосках с периодикой и в книжных магазинах, на развалах около вокзалов и станций метро. По подсчетам Ольги Шевченко, сделанным в 2001 г., суммарный тираж таких сборников, экземпляры которых были представлены в киоске средней руки, превышал 19 млн экземпляров в месяц [Шевченко 2001]. В сравнении со спросом на кроссворды в советское время это огромная цифра, которая свидетельствует о большой заинтересованности покупателей периодики в подобного рода продукции.

Гораздо чаще стали встречаться сканворды, представляющие собой упрощенную форму кроссвордов: клетки сканвордов контрастируют с лаконичным видом классического кроссворда своими размерами и тем, насколько плотно они зачастую заполняют страницу. Симметрия и аккуратность кроссвордной фигуры стали малозначимы, а содержание сканворда уже не требует углубленных познаний или развитых дедуктивных способностей. Сканворд, в отличие от кроссворда, пестрит короткими, неточными и неграмотными определениями, затрагивающими в основном бытовые темы; подобные головоломки ча- 
сто сопровождаются легкомысленными картинками, соседствуют с анекдотами и рекламой, изобилуют повторами и грубыми ошибками в составлении сетки. Строгая форма, симметричность и точность как важные в прошлом качества кроссворда уступают теперь простоте, «развлекательности» и увлекательности.

Можно говорить о двух типах кроссворда, которые соответствуют различным историческим периодам. Несомненно, культурные условия влияют на распространенность каждого из этих типов. Для России переход от кроссворда к сканворду предположительно связан с изменением практик потребления. Произошедшая трансформация вызывает интерес как с точки зрения видной невооруженным глазом разницы, которую можно заметить, если просмотреть пару случайных кроссвордов разного времени, так и с точки зрения представленных Ольгой Шевченко количественных показателей. Интересны как причины этих изменений, так и их последствия.

Интерпретация Шевченко, тем не менее, не кажется достаточно убедительной. Она связывает появление кроссвордной индустрии с судьбой образованной части общества. По ее мнению, кроссворд обладал компенсаторной функцией для многих квалифицированных специалистов, оставшихся без работы. Несмотря на снижение качества, кроссворды в определенной степени сохраняли статус «интеллектуального развлечения», позволяли представителям интеллигенции, вынужденно работавшим не по специальности, поддерживать ощущение принадлежности к интеллектуальному сообществу. «...Каждая заполненная в кроссворде колонка или строка, - пишет Шевченко - может с удовлетворением восприниматься игроком как очередное подтверждение того, что его культурный капитал, пусть и недооцениваемый работодателями и страной в целом, все же существует и даже позволяет коечего достигнуть, будь то денежный приз или признание попутчиков» [Шевченко 2001]. Тем не менее и экспансия индустрии кроссвордов, и изменение их формы и содержания не позволяют связывать кроссворды исключительно с интеллигенцией. С нашей точки зрения этот тезис противоречит отмеченному феномену «кроссвордного бума». Спрос на кроссворды был слишком велик, чтобы объяснять его только интересом достаточно узкой прослойки. Кроме того, не вполне понятно, насколько профессиональные знания и широкая эрудиция могут находить подтверждение посредством решения упрощенного по сравнению с обычным кроссвордом сканворда.

Борис Дубин и Наталия Зоркая в исследовании, посвященном чтению в 2000-е годы [Дубин, Зоркая 2008], пишут о вытеснении книжного чтения журнальным в 2000-е при небольшом сокращении чтения журналов в начале 1990-х, при этом отмечая такие функции журналов, как конструирование общественного мнения и создание чувства включенности в сообщество. Кроссворды они упоминают как элемент и газетной, и журнальной продукции. На момент проведения исследования $17 \%$ всех читателей газет решали кроссворды, а сами кроссвордные издания занимали 19\% от всей периодики. При этом среди потребителей кроссвордов лидировали «наименее обеспеченные слои населения» [Там же: 21]. Хотя в целом журналы были более популярны у молодежи и обеспеченной части населения, тематические издания, в которых чаще публиковались кроссворды, покупали респонденты среднего возраста (40 и более лет). В то же время, согласно проведенному Дубиным и Зоркой 
опросу, по какой-то причине газеты с кроссвордами чаще покупала обеспеченная молодежь. Сборники кроссвордов не выделялись в опросе в качестве отдельного пункта, однако был отмечен огромный спрос на развлекательные издания в целом в период, когда проводилось исследование.

В другой публикации Дубин [2010] отмечает, что кроссворды и сканворды являются одним из наиболее активно потребляемых типов периодики. По его данным, любую периодику активнее всего приобретают женщины, молодежь и городские жители, что объясняет огромное количество на прилавках сборников кроссвордов типа «Лиза. Кроссворды» (выбранных исключительно из женского развлекательного журнала «Лиза»). Как мы видим, в начале 2000-х годов спрос на кроссворды не обеспечивается целиком сообществом бывшей советской интеллигенции. Более того, Дубин фиксирует коммерциализацию и массовизацию печатных изданий после распада СССР, соотнося его с «распадом советской интеллигенции» [Там же: 225]. В свою очередь, изменение формы производства газет и журналов напрямую влияет на их содержание.

Больший объяснительный потенциал имеет замечание Шевченко по поводу чувства общности, которое, по ее предположению, кроссворд способен создать у читателя. Основой этого чувства становятся общие моральные принципы, выражаемые выбором «полезных» развлечений [Shevchenko 2007: 589]. Аналогичные соображения были высказаны и британской исследовательницей Оливией Свифт, опиравшейся в анализе кроссворда на теорию культуры Франкфуртской школы. По ее мнению, кроссворд не только становится поводом для кооперации реальных любителей кроссвордов, но также участвует в формировании воображаемых сообществ. Свифт представляет кроссворд в качестве одного из инструментов управления массами, утверждая, что посредством кроссворда навязывается определенный образ жизни [Swift 2007]. Последний тезис, на наш взгляд, требует дополнительных доказательств, однако основное направление объяснения социальных функций кроссворда кажется верным.

Соответственно, в нашем дальнейшем анализе мы постараемся развить обе линии рассуждений о кроссворде, которые были отмечены выше. С одной стороны, необходимо переосмыслить представление о кроссворде как интеллектуальном развлечении. Для реализации этой задачи нам представляется полезным обратиться к исследованиям кроссвордов, которые посвящены его функционированию в более рутинных контекстах - медицинских, педагогических и т. д. Выявление мнемонических функций кроссворда может стать отправной точкой для сближения кроссворда с загадкой как феноменом традиционной культуры. С другой стороны, нужно проанализировать трансформацию характера вопросов и текстового содержания в современном постсоветском кроссворде. Такого рода анализ позволит показать, как содержательные изменения кроссворда (в частности, связь с бытованием прецедентных текстов) свидетельствуют о его новых функциях в постсоветской повседневной культуре и о его близости к формам городского фольклора.

Как будет показано ниже, кроссворд сам по себе имеет потенциал инструмента некритического заучивания информации, а постсоветский кроссворд актуализирует это таким образом, что заучиваются представления о мире, позволяющие укрепить чувство принадлежности к группе. 


\section{2}

В современных журналах и газетах можно найти множество вариантов кроссворда. Могут различаться внешний вид кроссвордной фигуры, размеры клеток, а также текстовое содержание. Иногда вместо классических определений появляются картинки и ребусы. Стандартный вид постсоветского кроссворда - сканворд с крупными клетками, различными развлекательными дополнениями, картинками и простыми парами «вопрос - ответ». Однако все варианты кроссворда объединены тем, что слова в них пересекаются друг с другом там, где в них есть общие буквы, а также тем, что слова каким-то образом зашифрованы. В классическом варианте дается краткое определение слова, чуть более остроумное, чем словарное определение. Могут использоваться и другие способы шифровки.

Описанные общие черты устанавливают также общий способ решения, который подразумевают любые кроссворды. Этот способ становится очевиден, когда кроссворд используется как форма, будучи очищенным как от всякого развлекательного компонента, так и от мифологии «развлечения для эрудитов», которая своеобразно влияет на содержание. Такого рода кроссворды используются, к примеру, в естественнонаучных экспериментах, направленных на выявление когнитивных процессов, активирующихся при решении кроссвордов.

При том, что способ решения кроссворда не меняется, к «кроссвордному буму» начала 2000-х годов приводят изменения формы и содержания головоломки. Однако именно способ решения, предусмотренный любым кроссвордом, дает почву для того, чтобы эти изменения произошли. С нашей точки зрения, переход от кроссворда к сканворду создал иную ситуацию применения одной и той же мыслительной операции, что заставило кроссворд глубже проникнуть в культурный контекст, начав участвовать в более широком процессе воспроизводства культуры. Что важно отметить, операция решения кроссворда не имеет ничего общего с приписываемым ей развитием интеллектуальных способностей.

Мы попытаемся отделить основные когнитивные операции, связанные с решением кроссворда, чтобы увидеть специфику произошедшей с кроссвордом перемены и понять, как она может быть связана с повсеместным распространением этой головоломки именно в обозначенный период времени.

Обратимся к области, в которой кроссворд долгое время использовался в своей максимально «очищенной» форме, а именно к естественным наукам. Один из основных вопросов, встающих при его использовании, - позволяет ли кроссворд действительно «развить интеллект», т. е. провоцирует ли он тренировку каких-либо интеллектуальных навыков. Это оказывается крайне важным, когда речь идет о применении кроссвордов в медицине для предупреждения или торможения развития старческой деменции. Однако оказывается, что в большинстве случаев единственное, что провоцирует решение кроссвордов, - тренировка памяти. Кроссворд - хороший инструмент для этого, но аналитической работы он не требует. Именно этот факт позволяет рекомендовать его как один из способов по борьбе с болезнью Альцгеймера, характеризующейся в первую очередь потерей памяти ([Anderson et al. 2011: 922; Scalco, Reekum 2006: 201] и др.). Есть, впрочем, сомнения в том, что это 
действительно лечебная мера и наступление болезни Альцгеймера можно таким образом полностью предотвратить [Connor 2014: 215-216; Hambrick et al. 1999: 131], но некоторые исследования подтверждают восстановление и сохранение памяти у больных, решающих кроссворды [Scarmeas, Stern 2004; Wilson et al. 2002; Verghese et al. 2003]. Поскольку в кроссвордах содержатся элементарные сведения об устройстве повседневной жизни, они помогают больному получать и укреплять бытовые знания и способствуют восстановлению социальной идентичности.

Кроссворды используют в обучении как средство запоминания чего-либо: особенно эффективны они при изучении иностранных языков, когда требуется только запомнить связь между иностранным словом и его аналогом в родном языке. В педагогике существует большое количество исследований, посвященных использованию кроссвордов в процессе школьного и университетского обучения [Адаев 2015; Склярова 2011; Crossman, Crossman 1983; Davis et al. 2009; Htwe et al. 2012; Jaramillo et al. 2012]. Их эффективность была подтверждена экспериментами, проведенными среди школьников и студентов разных специальностей (см., например: [Davis et al. 2009; Saran, Kumar 2015] и др.). В экспериментах кроссворды демонстрируют наибольшую эффективность именно там, где никакой аналитической связи между вопросами и ответами нет.

Общий вопрос, которым задаются в смежных областях медицины и когнитивных наук, - способны ли кроссворды действительно затрагивать глубинные механизмы памяти. Иными словами, запоминается ли знание, включенное в кроссворд, или нет, и каким образом работает «вспоминание» ответа. Здесь возникает та же проблема рецепции, которую мы поднимаем в этой статье: «заучивается» ли включенное в кроссворд знание или оно приобретается аналитически?

Когнитивные науки предлагают одно из возможных описаний этого процесса. В работе [Thanasuan 2015] приводится оригинальное исследование того, насколько кроссворды и близкие к ним языковые головоломки действительно способны помочь запоминать иностранные слова и их связь с определениями либо аналогами в родном языке. В сравнении с другими головоломками кроссворд обнаруживает значительную эффективность, что обусловлено своеобразностью процесса его решения. Автор исследования опирается на теорию памяти Шиффрина и Аткинсона, широко используемую в когнитивных науках [Shiffrin, Atkinson 1969]. Согласно этой теории решение кроссвордов может быть связано с процессом открытия доступа к памяти о связях слов между собой для ответа на вопрос. Запоминается связь ключа и ответа, но не возникает глубинного понимания связи понятий, которые стоят за словами. Что интересно, и при отгадывании слов через определения, и при переводе иностранного аналога задействуются одни и те же когнитивные механизмы. Ответ вспоминается ассоциативным образом, т. е. это могут быть любые слова, связь между которыми произвольна. При этом в исследовании [Thanasuan 2015] не было обнаружено подключения к процессу решения других когнитивных структур.

Имея дело с различными сферами применения кроссворда, мы наталкиваемся на повторяющиеся выводы относительно самого устройства данного типа головоломки. Кроссворд подразумевает не аналитическую или интеллек- 
туальную работу, а вспоминание и заучивание ассоциативных связей между словами. При этом, по сути, фразы-вопросы и ответы могут быть любыми. Решать кроссворд позволяет своевременное появление требуемых ассоциаций, как и в случае с кроссвордом на знание языка.

Решение кроссвордов означает проверку знания и его закрепление посредством прицельной акцентуации и повторения ассоциации. Ниже будет показано, что через смену текстуального содержания именно это свойство способствует широкому внедрению кроссворда в формирующееся поле культуры, и именно оно рождает чувство причастности к группе у решающего кроссворд. Подобные характеристики свойственны некоторым фольклорным явлениям. В частности, можно отметить близость постсоветского кроссворда и загадки, что позволяет задать вопрос о схожести их функций в культуре.

Алексей Юдин [1999: 207] называет загадки «экзаменационным вопросом» на знание мифологического языка, а их загадывание - «древнейшим механизмом обучения»: ответ необходимо выучить, нет смысла пытаться догадаться самостоятельно, что означает тот или иной образ в загадке. Загадка содержит знания о некой символической системе, описывающей устройство мифологического мира. Здесь важно указание на обучающую функцию загадки. Можно сказать, что «массовый» кроссворд точно так же содержит сведения об устройстве повседневной жизни и «обучает», закрепляя знание, являющееся достоянием социальной группы. И в загадке, и в постперестроечном кроссворде логическая или причинно-следственная связи между вопросом и ответом перестают прослеживаться, фактически просто заучиваются пары «вопрос - ответ». Подобные идеи относительно любых кроссвордов высказывают некоторые российские авторы [Волкова 2011; Захаренко 1998], но в постперестроечных сканвордах связь с загадкой и бытом отражена гораздо ярче.

Интересно, что, как и кроссворд, загадка как фольклорная форма также легко превращается в заучивание связок «вопрос - ответ». Эти лингвистические конструкции зачастую отрываются от своих референтов. Наблюдая то, как дети заучивают загадки, можно заметить, что ответ достаточно редко ими «находится». Значение фразы может быть понято ими неправильно или не понято вовсе - тем не менее ответ привязывается к вопросу, ср.: Зимой и летом одним цветом = Елка. Хотя загадка скорее отсылает к информации о том, что ель - вечнозеленое растение (это подразумевает одновременно и круглогодичное сохранение листвы, и сохранение последней своего цвета), дети понимают смысл загадки чересчур дословно. Понимание иявета в колористическом аспекте, без привязки к цветению и листве, на самом деле не позволяет найти ответ на эту загадку. Цвет сохраняет круглый год все, что угодно, кроме листьев лиственных деревьев, и ответ может быть любым, от «апельсина» до «Ты, папа», как иногда шутят дети, прекрасно улавливая некоторую абсурдность неправильно понятого вопроса. Тем не менее эта связка вопроса и ответа заучивается, и при повторении вопроса у любого человека, выросшего на территории бывшего СССР, ответ возникает незамедлительно.

Знание, включенное в загадки, часто оказывается устаревшим и не имеющим отношения к повседневности ребенка, что дополнительно препятствует пониманию и устраняет возможность действительного аналитического «разгадывания» загадки. С кроссвордом происходит то же самое: связи между словами ассоциа- 
тивны или недостаточно прояснены, потому ответ заучивается. Но когда вопросы касаются нормативных установок, содержат повседневные суждения, заученные связки приобретают значение бытовых истин и удачно «вписываются» в повседневное мышление. Этот эффект, по-видимому, близок к тому, как устроена метафора - другая языковая структура, имеющая непосредственную связь с когнитивным аппаратом и повседневным мышлением. Метафора создает связь между понятиями, основанную на ассоциации. В отличие от примера с кроссвордом, она, однако, способна обогатить представление и сделать его более объемным.

Метафора может быть основным элементом загадки. Она обеспечивает ту иррациональность, которая необходима для сокрытия знаний и делает аналитическое решение загадки невозможным. Иррациональность же затрудняет возможность проверки знания или попытки его деконструировать. Кроссвордный ключ может быть метафорой в художественном смысле, как в паре Сердиее атомной станции = Реактор. Метафора здесь имеет описательное значение, решение предлагается через последовательность ассоциаций. Однако встречаются случаи, когда основной кроссвордной пары становятся метафоры, напрямую отсылающие к неким базовым представлениям о ценностях или устройстве мира: Сила интеллектуала = Знания. Здесь фигурирует формула «знание сила», описанная, к примеру, Дж. Лакоффом и М. Джонсоном как одна из базовых культурных метафор, конструирующих представления о мире у человека модерна [Лакофф, Джонсон 2004: 246]. Они же пишут о метафоре как о своего рода способе организации «нормативного» мышления [Там же: 25] (ср. [Гудков 1994: 20]). Иными словами, близость кроссвордной пары «вопрос — ответ» метафоре наделяет кроссворд способностью организовать мышление подобно ей. Сила метафоры заключается именно в типе связей между понятиями, которые она устанавливает. В работах [Гудков 1994; Лакофф, Джонсон 2004] показано, что подобные структуры могут в значительной степени быть источником представлений о мире, оставаясь «на фоне», будучи не до конца осознанными. Мы предполагаем, что связки слов в кроссворде действуют примерно так же.

Таким образом, обращение к медицинским и педагогическим исследованиям кроссворда побуждает пересмотреть представление о кроссворде как интеллектуальном развлечении. Репродуктивную функцию в современной культуре скорее стоит мыслить по аналогии с функционированием загадки в традиционной культуре: загадка участвует в воспроизводстве мифологической картины мира, в то время как современный кроссворд - скорее повседневной. Иными словами, формальные изменения головоломки в сторону интуитивно понимаемого «упрощения» при сохранении основных ее структурных особенностей привели к тому, что кроссворд оказался встроен в быт более плотно и его функция сблизилась с функцией загадки, поскольку тип организации включенного в кроссворд знания оказался по воздействию близок метафоре. Бытовые знания, включенные в кроссворд, способствовали тому, что он начал участвовать в формировании повседневного мышления.

Задача следующей части данной статьи - проанализировать формальные изменения кроссворда, чтобы получить представление о том, как аспекты повседневного мышления и картины мира проникают в него, подменяя собой энциклопедическое знание. Важным здесь оказывается обращение непосредственно к сообществу кроссвордистов: к написанным ими электронным или же бумажным статьям, книгам, а также к обсуждениям на форумах. 
Изменения принципов составления кроссвордов привели их в конце концов к той форме, которую мы наблюдаем сейчас, и в результате спрос на них увеличился.

Советские составители кроссвордов ориентировались на классические примеры. Их опыт в конце концов выкристаллизовался в руководствах по составлению кроссвордов, которые были написаны в том числе уже после перестройки. Даже в источниках начала 2000-х годов по-прежнему описываются качества и критерии, которые скорее характерны для советских и классических кроссвордов, чем для постперестроечных.

Создание кроссворда предстает в этих пособиях как более или менее искусное ремесло. Их авторы уделяют довольно большое внимание внешнему виду головоломок. Кроссвордная сетка рассматривается как самодостаточная, даже живописная форма. Ее «эстетичность», «красота» и «гармоничность» связываются с симметрией и формальной законченностью ([Виноградова 1998; Ищенко 2012; Зотов 1999] и др.).

Строгие требования предъявляются и к содержанию. Слова и определения должны подбираться тщательно и составлять единство с кроссвордной фигурой. В кроссворд нельзя включать аббревиатуры, использовать для пары «вопрос - ответ» однокоренные и однородные слова. Определение должно быть точным, но в то же время оно не должно быть «прозрачным», как и не должно содержать избыточную информацию. Существует и множество других разнообразных правил: не начинать формулировку вопроса с цифры, не использовать названия болезней, не разбивать определение на несколько предложений и пр. ([Балазанов б. г. (a); (b); (c); Зотов 1999; Маев 1998; Составление б. г.] и др.). Составление кроссворда становится вопросом поиска наиболее подходящих слов и ключей. Тонкость подбора ключей определяет, насколько захватывающей получится головоломка.

Решение классического кроссворда в основном зависит от общей эрудиции. Чтобы решить кроссворд, нужно знать столицы стран, названия рек, обладать тривиальными знаниями из различных областей человеческой деятельности. Правилами составления кроссвордов исключаются любые слова и определения, между которыми нет четко установленной связи (посредством энциклопедического или словарного определения). Важно отметить, что, какими бы ни были эти знания, они требуют заучивания.

Стоит остановиться более подробно на анализе вышедшей в 1998 г. книги М. Маева «Решайте и составляйте», которая достаточно хорошо иллюстрирует, каким должен быть кроссворд в идеалистическом представлении прошлого века [Маев 1998]. Основное достоинство этой книги состоит в том, что в ней собрано достаточно большое количество примеров, подкрепляющих практическое руководство, и свод правил по составлению кроссвордов, которые являются комплексным обобщением прошлого опыта работы автора с советскими кроссвордами.

Маев старается выбирать неожиданные для читателя слова и делает вопрос к слову (ключ) менее очевидным, чем определение в словаре. Заимствуя стандартное определение, он заменяет одно из слов в вопросе нетипичным синонимом. Особенность кроссвордов Маева в том, что порой о значении слова 
можно догадаться путем последовательного размышления. В прошлом такого рода ключи часто встречались в «Науке и жизни». Это делает возможным решение кроссворда даже без обладания специальными знаниями. Ответ на намеренно усложненный вопрос оказывается проще, чем это можно предположить с первого взгляда: Водоем с признаками стагнации = Болото [Маев 1998: 51]. Приведенный пример - не самое типичное описание такого природного явления, как болото. Но решающий, последовательно «разворачивая» ключ, проникает в его значение и догадывается, что имелось в виду.

Иногда при составлении вопросов Маев использует приемы, свойственные западным кроссвордам. Допустим, объединяет омонимы в одном определении: Музыкальный интервал, близкий воспитанному человеку = Такт [Там же: 51]. Из редких слов он иногда выбирает то, которое решающий может знать по какимлибо произведениям искусства, шуткам, расхожим выражениям: Типографский шрифт = Нонпарель [Там же: 132] (слово может быть известно по книге Александра Козачинского «Зеленый фургон»). Ирония, полушутливые формулировки - особенность, позволяющая избежать прямого морализаторства, которое сопутствует ауре «культурного» и «интеллектуального развлечения». Усложнение ключа дополняет процесс лексического вспоминания интеллектуальной работой, при этом сохраняется «обучающее» свойство кроссворда.

В отличие от этих кроссвордов, которые, хотя и были изданы в 1998 г., но сделаны «в лучших традициях» советского кроссворда, типичный постсоветский сканворд характеризуется упрощенной формой, что, по-видимому, связано с увеличением количества соответствующих изданий, требующих производства огромного количества головоломок в кратчайшие сроки. Составители кроссвордов охотно освоили компьютерные программы, позволяющие генерировать сетку автоматически. Вопрос внешней привлекательности полученной сетки отходит на задний план. Некоторые из программ способны даже заполнить сетку словами, так что составителю остается лишь поработать с определениями. Скорость «штампования» новых кроссвордов не оставляет времени для более усердной работы над каждым ${ }^{1}$. В ситуации массового тиражирования кроссворд утрачивает черты «авторского» продукта, возникает вопрос и о планке качества. Среди составителей кроссвордов возникает дискуссия о том, что в создании кроссворда можно доверить программе, а что остается уделом исключительно кроссвордиста. Прежде всего речь идет о придумывании слов и ключей. Чаще всего полностью автоматизированному составлению, когда программа и создает сетку, и заполняет ее словами, и подыскивает к словам определения, составители не доверяют ${ }^{2}$. Только автоматизированное создание самого чертежа сканворда стало с какого-то момента привычным: критерии симметрии и «красоты» перестали быть такими уж важными, осталось лишь требование оставлять минимальное количество черных клеток между словами. Обычно обсуждается, доверять ли программе придумывание слов и определений, и если да, то до какой степени. Некоторые допускают переложение обеих задач на программу, только если определения

${ }^{1}$ См., например: [Губарь 2015]; ср. также инструменты для создания кроссвордов, размещенные в Интернете: http://kazus.ru/programs/viewdownload/kz_0/cid_65.html; http://alexbestbusiness.com/poleznye-instrumenty/bystro-sozdat-krossvord-programmy-vozmozhnosti.html.

2 Для примера подобных программ см.: [Программы 2010-2012]. 
затем корректируются вручную составителем. Некоторые составители кроссвордов считают, что придумывать определения желательно самостоятельно с нуля, иначе они будут, как выражается кроссвордист Балазанов, скучными, «не блещущими разнообразием». Человек, как предполагается, обладает большей изобретательностью, чувством юмора, «смекалкой» и поэтому должен придумывать ключи сам. Когда речь заходит о содержании, а не о форме, составители могут отказываться от помощи программ вообще (см.: [Балазанов б. г. (а); Зотов 1999; Программы 2010-2012; Разработка 2005] и др.).

Однако еще более существенным фактором оказывается внутренняя ориентация составителя на определенную аудиторию, которая проявляется особенно ярко в случае тематических журналов, например, «Лиза», «Охота и рыбалка» и т. п. Скорость решения и простота - необходимые качества сканворда, а значит, ответ должен вспоминаться быстро. Связи между словами должны быть уже известны решающему и в повседневной жизни актуализироваться часто. Сканворды начинают апеллировать к повседневному знанию и бытовым представлениям об устройстве мира. Ответить на вопросы удается быстро, поскольку они касаются того повседневного, типичного, которое не осмысляется, причем для подтверждения правильности ответа нет необходимости обращаться к энциклопедии или словарю. Плотная формальная взаимосвязь слов через их пересечения в кроссвордной сетке сама по себе становится критерием истинности: если заученная связь «вопрос - ответ» верна, соседние слова будут пересекаться со вписанным словом без противоречий. Если в случае с советским кроссвордом можно было при необходимости найти аналитическое или практическое подтверждение правильности ответа и он подразумевал косвенные отсылки такого рода, то постсоветский кроссворд тяготеет к замыканию на себе, бесконечной самореференции. Таким образом, становится возможным принятие за истину бессмысленных, туманных или противоречивых фраз. Устройство сканворда содержит в самом себе условие истинности, которого оказывается достаточно.

Производитель кроссворда существует в том же культурном поле, что и аудитория, и «подстраивание» кроссворда под аудиторию не обязательно должно происходить осознанно. Современный кроссворд - это форма, в которой сознательное авторство исчезает. Составитель может корректировать содержимое кроссворда, исходя из вкусов аудитории, например, добавляя больше вопросов про домашние хлопоты в кроссворды от «Лизы» или названия рыболовных снастей в кроссворды из «Охоты и рыбалки». Тем не менее сам составитель в спешке не совершает той интеллектуальной работы, которая от него требуется, и включает в кроссворд вещи, очевидные для него. Штампованные представления, связи, на которых базируются эти вопросы, принадлежат в равной степени и составителю, и решающему. Кроссворд как явление культуры скорее является частью анонимного процесса формирования культурной базы - как это происходит с фольклором.

Проиллюстрировать этот тезис поможет пилотное изучение текстовой составляющей кроссвордов ${ }^{3}$. В данном случае рассматривается «идеальный

${ }^{3}$ В данном случае не утверждается, что полученный материал репрезентативен - скорее он мог бы стать отправной точкой для более систематического изучения кроссвордов на конкретной выборке. Цель следующего рассуждения - проиллюстрировать выводы, а не провести систематическое исследование. 
тип» постсоветского кроссворда. Выводы основаны на наблюдениях и решении подобных головоломок разного вида в течение продолжительного времени. Целью исследования при этом не является составление систематической типологии вопросов. Мы лишь совершим попытку указать на несколько основных типов ключей, которые репрезентативны для современного массового кроссворда, но не могли бы встретиться в кроссвордах прошлого века, поскольку их посчитали бы нарушающими принципы составления: они включают личные оценки, недостаточно прозрачны, могут касаться «скользких» тем, содержат тавтологии и т. д. Это позволит наметить определенные тенденции изменения текстового содержимого кроссвордов ${ }^{4}$.

Кроссворды прошлого века должны были базироваться на энциклопедических знаниях, так или иначе доступных широкой аудитории кроссвордов. Типичны были вопросы «с подковыркой», остроумные, требующие аналитического решения или же простые «проверки знаний», базирующиеся на строгих определениях, как в паре Республика с Сыктывкаром = Коми $[100$ новых сканвордов 2016]. В кроссворды могли попадать и малоизвестные термины. Представляет интерес то, как редкие слова, которые регулярно вставляют в кроссворды из-за удобства, заучиваются широкой аудиторией вне контекста их использования, как это произошло, по-видимому, с парой Взрослое насекомое = Имаго [Там же].

В постперестроечных кроссвордах появляются вопросы, отсылающие уже не к эрудиции, а скорее к культурно-социальному фону целевой аудитории. Их невозможно решить с помощью последовательного рассуждения - необходимо знать детали быта и повседневности той группы, к которой апеллирует журнал. К примеру: Промокашка на столе = Салфетка [Лиза 2016а] (бумажные салфетки лежат на столе, чтобы промокнуть, если что-нибудь разольется); Раздутая кукуруза для киноманов = Попкорн [Крот 2016b] (попкорн принято есть в кино); «Кофе» в детском саду = Какао [Лиза 2016а] (детям дают какао, когда те просят кофе; какао считается напитком для детей, а кофе - для взрослых; в детском саду детям дают какао).

Еще большим отходом от «канонов» составления кроссворда можно считать вопросы, затрагивающие стереотипы, связанные с какими-либо предметами или явлениями, или их оценочные характеристики. Содержащиеся в них сведения о том, как надо относиться к тому или иному предмету, иногда можно оправдать необходимостью использовать их в повседневных ситуациях, и тогда они напоминают замаскированный совет. Допустим: Беда nолных женщцин = Eда [Лёшкин Кот 2016] (подразумевается, что еда является проблемой для полных, вероятно, источником проблемной полноты); Приставания сочииолога = Опрос [Путёвый 2016]; Чудак из неформальных = Панк [Там же].

Именно через вопросы о быте, о нормативном в обществе отношении к вещам, в кроссворд проникают представления о повседневной жизни и практические повседневные знания. Они связывают кроссворд с сообществом,

${ }^{4}$ В качестве материала для исследования были проанализированы, наряду с цитируемыми, следующие источники: [Дарья 2016; Дорожный сканворд 2016; Крот 2016а; 2016с; 2016d; 2016е; Лиза 2016b; 2016с; Малков 1997; Реши 2016; Сборная солянка 2016; 1000 сканвордов 2016; Хит-сканворд 2016], а также сайт EasyCross (easycross.chat.ru). 
создающим и потребляющим его. Особенность этих двух типов вопросов в формулировках ключей, которые были бы немыслимы для «классического» кроссворда. Благодаря обучающей функции кроссворда именно такие формулировки связываются с ответом в сознании решающего. То есть кроссворд функционирует как механизм, позволяющий решающему без какой-либо специальной аналитической работы «заучивать» представления о мире, содержащиеся в кроссворде.

Изменения в содержании, которые мы замечаем, таким образом, связаны с проникновением своего рода частных суждений, которые являются или могут стать общими для группы. Суждения могут быть основаны на частном опыте, расхожих представлениях, клише или на эмоциональном впечатлении. Вызов подобных ассоциаций и дополнительное их проговаривание в ситуации, когда ответ наделяется «истинностью» в кроссвордной сетке, должен укоренять в сообществе коллективные представления. Таким образом, вероятно, укрепляется чувство принадлежности сообществу у решающего.

К. А. Богданов [2001] предлагает понимать «прецедентные тексты» как тексты, содержание которых отходит на второй план перед их социальными функциями. На их основе можно составить представление о фольклоре определенного сообщества: в их число могут входить пословицы, клишированные фразы, загадки, цитаты из популярных произведений. Знание этих текстов определяет принадлежность индивида к социальной группе, при этом тексты широко включены в традицию. Прецедентные тексты могут существовать благодаря наличию у индивида фоновых знаний, т. е. не осмысляемых «клишированных утверждений», функциональность которых важнее их содержания. Работа Богданова предлагает удобный аппарат для объяснения феномена кроссвордов. Отличие постперестроечного кроссворда от его классического варианта заключается в том, что упрощенный кроссворд начинает все больше напоминать прецедентный текст. Это и позволяет кроссворду апеллировать к представлениям о легитимных эмоциях и знаниям о повседневных практиках, которые воплощены в фоновом знании аудитории. «В целом фольклорный дискурс может рассматриваться, с учетом вышесказанного, как поддерживающий такие коммуникативные стратегии общества, благодаря которым идеологические реакции коллектива могут быть до известной степени спрогнозированными» [Там же: 56]. Фольклорные тексты могут быть использованы в идеологических целях — то же самое возможно и в случае кроссвордов, однако это далеко не обязательно.

Именно так постсоветский кроссворд оказывается способен поддерживать и укреплять чувство общности через усиление коллективных представлений: в отличие от классических образцов, он не «дополняет» картину мира добавочными знаниями, которые не используются в быту, а затрагивает непосредственно структуру повседневных представлений о мире, через свое содержание формируя убеждения, которые являются опорными для сообщества. Если кроссворд классического образца и был на это способен, то причина лежала не в его содержании, не в его внутренней структуре, а в том, какие социальные смыслы наслаивались «поверх» него в процессе использования. 
$* * *$

Таким образом, отмеченный Ольгой Шевченко резкий рост популярности кроссвордов после распада Советского Союза нельзя объяснить только повысившимся спросом на них у представителей бывшей советской интеллигенции. Замечание о том, что кроссворд позволяет создать чувство общности, важно, хотя это вряд ли может быть справедливо в случае советского кроссворда, который скорее отчуждал решающего от массива информации, включенной в кроссворд. Кроссворд был нацелен на сохранение некоторой дистанции, за счет которой создавался его имидж «интеллектуального» развлечения. Постсоветский кроссворд, напротив, создал условия для усиления чувства включенности в сообщество, поскольку его содержание стало касаться близкого, понятного, повседневного.

Сообщество, которое здесь упоминается, несомненно, остается «воображаемым», и не всегда возможно четко очертить его границы. Вероятно, часто этим сообществом можно считать целевую аудиторию издания, если этот образ попадает в цель, соответствуя реальности. Фигурально говоря, это то «мы», которое по ни мает упомянутую в кроссворде ситуацию, з н а е т эту традицию, пользуется этими предметами. Сканворд явным образом выражает такое «мы», создавая ощущение, которое можно характеризовать словами «это по-нашему». Особое свойство кроссвордов как вида головоломки позволяет им раскрыться как инструментам заучивания связок слов при исключении аналитических или критических операций мышления, что и делает возможным такое обобщение.

Изменение формы и текстуального содержания кроссворда, его становление сканвордом приводят к тому, что он оказывается более плотно включен в повседневность. Именно эта трансформация влечет за собой популяризацию кроссворда.

Здесь важно отметить, что кроссворд включен в повседневность как своего рода «фоновое явление». Это значит, что тренд на сканворды и кроссворды почти никак не рефлексируется в массовой культуре. Иными словами, массовая культура не отражает популярность кроссворда как «моду». Всплеск популярности кроссвордов фиксируется только статистически, как увеличение спроса и количества разнообразных изданий (например, см.: [Дубин 2010; Shevchenko 2007]). Условия для изменения функции кроссворда в культуре создало именно его формальное упрощение: он сблизился с фольклорными формами и участвует в воспроизводстве культурной базы наравне с ними. Изменение функции привело к изменению места явления в культуре, сделав его более распространенным.

\section{Источники}

Маев 1998 - Маев М. Решайте и составляйте. 1998. М.: Букмэн, 1998.

McKie 2013 - McKie D. 100 years of crosswords: The first appeared in New York on 21.12.1913 // The Guardian. 2013. December 20. URL: https://www.theguardian.com/crosswords/2013/dec/20/100-years-crosswords-first-new-york. 
Балазанов б. г. (а) - [Балазанов В.] Как создать интересный и качественный кроссворд? Ч. 2 // Шевели мозговой извилиной: Сайт онлайн-кроссвордов, сканвордов, кейвордов, японских кроссвордов и прочих головоломок. URL: http://crossword-best.ru/Statji-okrossvordah $12 . \mathrm{htm}$.

Балазанов б. г. (b) — [Балазанов В.] Кроссворд — «разгильдяй» или «аккуратист»? Некоторые особенности правил составления кроссвордов // Шевели мозговой извилиной: Сайт онлайн-кроссвордов, сканвордов, кейвордов, японских кроссвордов и прочих головоломок. URL: http://crossword-best.ru/Statji-o-krossvordah_04.htm.

Балазанов б. г. (c) - [Балазанов B.] Основные требования к сканвордным стрелкам. Виды и различия стрелок в сканвордах // Шевели мозговой извилиной: Сайт онлайн-кроссвордов, сканвордов, кейвордов, японских кроссвордов и прочих головоломок. URL: http://crossword-best.ru/Statji-o-krossvordah_15.htm.

Виноградова 1998 - Виноградова А. И. Решение кроссвордов. От новичка к мастеру. СПб.: КАРО, 1998.

Губарь 2015 - Губарь В. Место кроссвордов в современном мире или переход от совка к XXI веку // Skanword.com. 2015. 30 авг. URL: http://skanvord.com/skanvord-krossvordnye-stati/mesto-krossvordov-v-sovremennom-mire-ili-perehod-ot-sovka-k-xxi-veku.

Дарья 2016 - Дарья. Сканворд: [Ж-л; Санкт-Петербург]. 2016. №3.

Дорожный сканворд 2016 - Дорожный сканворд: [Ж-л; Москва]. 2016. № 3.

Зотов 1999 - Зотов П. М. Как составить и решить кроссворд. М.: ТРИЭН, 1999.

Ищенко 2012 - [Ищенко Е.] Правила составления кроссвордов // Эрудит. 2012. 11 дек.

URL: http://erudit-menu.ru/plugins/dif_news/dif_news.php?0.view.97.

Крот 2016b - Крот - Настоящий: [Газ.; Владимир]. 2016. № 1.

Крот 2016с - Крот - Скандинавские кроссворды: [Газ.; Владимир]. 2016. № 8.

Крот 2016d - Крот - Скандинавские кроссворды: [Газ.; Владимир]. Спецвып. «Праздничный». 2016. № 3.

Крот 2016е - Крот - Слог-сканворды: [Газ.; Владимир]. 2016. № 3.

Крот 2016а - Крот - Дешевые сканворды: [Газ.; Владимир]. 2016. № 5.

Лёшкин Кот 2016 - Лёшкин Кот [Ж-л; Москва]. 2016. № 3.

Лиза 2016b - Лиза. Лабиринт кроссвордов: [Ж-л; Москва]. 2016. № 3.

Лиза 2016c - Лиза. Счастливый момент! Журнал суперсканвордов [Москва]. 2016. № 3.

Лиза 2016а - Лиза. Кросс-коктейль: [Ж-л; Москва]. 2016. № 3.

Малков 1997 - Малков Ю. Г. Краткий словарь кроссвордиста. Томск: НПТ «Курсив», 1997.

Пискунов 2000 - [Пискунов А.] Из истории кроссворда // Интерактивные кроссворды. [2000]. URL: http://students.uni-vologda.ac.ru/pages/pm97/paa/CROSSGEN/history.html.

Программы 2010-2012 - Программы для составления кроссвордов // Город кроссвордов. 2010-2012. URL: http://crosswordscity.ru/plugins/content/content.php?cat.7.

Путёвый 2016 - Путёвый: [Ж-л; Москва]. 2016. № 3.

Разработка 2005 - Разработка и публикация кроссвордов, сканвордов: [Ветка на форуме] // Diforum.ru. 2005. URL: http://www.diforum.ru/topic/2730-328-разработка-ипубликация-кроссвордов-сканвордов.

Реши 2016 - Реши для души. Сборник сканвордов: [Ж-л; Москва]. 2016. № 3.

Сборная солянка 2016 - Сборная солянка. 150 сканвордов, кроссвордов и судоку: [Ж-л; Москва]. 2016. № 3.

Составление б. г. - Составление кроссвордов // Народные сканворды. [2002-2008]. URL: http://scanwords.narod.ru/3.html. 
Хит-сканворд 2016 - Хит-сканворд: [Ж-л; Москва]. 2016. № 3(147).

100 новых сканвордов 2016 - 100 новых сканвордов: [Ж-л; Санкт-Петербург]. 2016. № 3. 1000 сканвордов 2016 - 1000 сканвордов: [Ж-л; Москва]. 2016. № 3.

\section{Литература}

Адаев 2015 - Адаев И. А. Формирование профессиональных компетенций у будущих учителей химии с использованием информационных технологий: Дис. ... канд. пед. наук / Чуваш. гос. пед. ун-т им. И. Я. Яковлева. Чебоксары, 2015.

Богданов 2001 - Богданов К. А. Повседневность и мифология: Исследования по семиотике фольклорной действительности. СПб.: Искусство-СПБ, 2001.

Волкова 2011 - Волкова М. В. Загадка и кроссворд как типы текста: семантический и прагматический аспекты: Дис. ... канд. филол. наук / Смоленский гос. ун-т. Смоленск, 2011.

Гудков $1994-$ - уудков Л. Д. Метафора и рациональность как проблема социальной эпистемологии. М.: РУСИНА, 1994.

Дубин 2010 - Дубин Б. Книга - чтение - библиотека: Тенденции недавних лет и проблемы нынешнего дня // Дубин Б. Классика, после и рядом: Социологические очерки о литературе и культуре. М.: Нов. лит. обозрение, 2010. С. 225-249.

Дубин, Зоркая 2008 - Дубин Б., Зоркая Н. Чтение и общество в России 2000-х годов // Вестник общественного мнения. 2008. № 6. С. 30-36.

Захаренко 1998 - Захаренко И. В. Русская когнитивная база и русское культурное пространство в зеркале кроссвордов // Язык, сознание, коммуникация: Сб. ст. Вып. 5 / Ред. В. В. Красных, А. И. Изотов. М.: Филология, 1998. С. 32-40.

Лакофф, Джонсон 2004 - Лакофф Дж., Джонсон М. Метафоры, которыми мы живем / Пер. с англ. А. Н. Баранова, А. В. Морозовой; Под ред. и с предисл. А. Н. Баранова. M.: УРCC, 2004.

Склярова $2011-$ Склярова $E$. E. Использование приемов медиадидактики для активизации познавательной деятельности студентов // Проблемы и перспективы развития образования в России. № 12. 2011. С. 156-163.

Шевченко 2001 - Шевченко О. Кроссворд. Лекарство от скуки из девяти букв // Неприкосновенный запас. 2001. № 4. Цит. по электрон. версии. URL: https://magazines.gorky. media/nz/2001/4/krossvord-lekarstvo-ot-skuki-iz-devyati-bukv.html.

Юдин 1999 - Юдин А. В. Русская народная духовная культура: Учеб. пособие для студентов вузов. М.: Высш. школа, 1999.

Anderson et al. 2011 - Anderson L. N., McCaul K. D., Langley L. K. Common-sense beliefs about the prevention of Alzheimer's disease // Aging and Mental Health. Vol. 15. No. 7. P. 922-931.

Connor 2014 - Connor $A$. The crossword century: 100 years of witty wordplay, ingenious puzzles, and linguistic mischief. New York: Gotham Books, 2014.

Crossman, Crossman 1983 - Crossman E. K., Crossman S. M. The crossword puzzle as a teaching tool // Teaching of Psychology. Vol. 10. No. 2. 1983. P. 98-99.

Davis et al. 2009 - Davis T. M, Shepherd B., Zwiefelhofer T. Reviewing for exams: Do crossword puzzles help in the success of student learning? // The Journal of Effective Teaching. Vol. 9. No. 3. 2009. P. 4-10.

Hambrick et al. 1999 - Hambrick D. Z., Salthouse T. A., Meinz E. J. Predictors of crossword puzzle proficiency and moderators of age-cognition relations // Journal of Experimental Psychology: General. Vol. 128. No. 2. 1999. P. 131-164.

Htwe 2012 - Htwe T. T., Sabaridah I., Rajyaguru K. M., Mazidah A. M. Pathology crossword competition: An active and easy way of learning pathology in undergraduate medical education // Singapore Medical Journal. Vol. 53. No. 2. 2012. P. 121-123. 
Jaramillo et al. 2012 - Jaramillo C. M. Z., Losada B. M., Fekula M. J. Designing and solving crossword puzzles: Examining efficacy in a classroom exercise // Developments in Business Simulation and Experiential Learning. Vol. 39. 2012. P: 213-222.

Saran, Kumar 2015 - Saran R., Kumar S. Use of crossword puzzle as a teaching aid to facilitate active learning in dental materials // Indian Journal of Applied Research. Vol. 5. No. 4. 2015. P. 456-457.

Scalco, Reekum 2006 - Scalco M. Z., Reekum R. Prevention of Alzheimer disease. Encouraging evidence // Canadian Family Physician. Medecin de famille canadien. Vol. 52. 2006. P. 200-207.

Scarmeas, Stern 2004 - Scarmeas N., Stern Y. Cognitive reserve: Implications for diagnosis and prevention of Alzheimer's disease // Current Neurology and Neuroscience Reports. Vol. 4. No. 5. P. 374-380.

Shevchenko 2007 - Shevchenko O. 'Wiggle your wits!' Social restructuring and the transformation of entertainment genres in today's Russia // Social Identities. Vol. 13. No. 5. 2007. P. 577-595.

Shiffrin, Atkinson 1969 - Shiffrin R. M., Atkinson R. C. Storage and retrieval processes in longterm memory // Psychological Review. Vol. 76. No. 2. P. 179-193.

Swift 2007 - Swift $O$. The people's puzzle: Crossword and knowledge politics. London: Goldsmiths College, 2007. (Goldsmiths Anthropology Research Papers; No. 13).

Thanasuan 2015 - Thanasuan K. Using cognitive word games to promote lexical memory access: A dissertation submitted in partial fulfillment of the requirements for the degree of doctor of philosophy in Applied Cognitive Science and Human Factors / Michigan Technological University. 2015. URL: https://pdfs.semanticscholar.org/3e62/d3bb36cdf85ef25ba3b$16245 \mathrm{dc} 8 \mathrm{~b} 44 \mathrm{~b} 38 \mathrm{~b} 0 \mathrm{a} . \mathrm{pdf}$.

Verghese et al. 2003 - Verghese J., Lipton R. B., Katz M. J., Hall C. B., Derby C. A., Kuslansky G., Ambrose A. F., Sliwinski M., Buschke H. Leisure activities and the risk of dementia in the elderly // The New England Journal of Medicine. Vol. 348. No. 25. P. 2508-2516.

Wilson et al. 2002 - Wilson R. S., Bennett D. A., Bienias J. L., Aggarwal N. T., Mendes De Leon C. F., Morris M. C., Schneider J. A., Evans D. A. Cognitive activity and incident AD in a population-based sample of older persons // Neurology. Vol. 59. No. 12. P. 1910-1914.

\section{References}

Adaev, I. A. (2015). Formirovanie professional'nykh kompetentsii u budushchikh uchitelei khimii s ispol'zovaniem informatsionnykh tekhnologii [Forming professional competences in future chemistry teachers through the use of informational technologies] (Cand. Sci. (Pedagogical Studies) Thesis, Yakovlev Chuvash State Pedagogical University). Cheboksary. (In Russian).

Anderson, L. N., McCaul, K. D., Langley, L. K. (2001). Common-sense beliefs about the prevention of Alzheimer's disease. Aging and Mental Health, 15(7), 922-931.

Bogdanov, K. A. (2001). Povsednevnost'i mifologiia: Issledovaniia po semiotike fol 'klornoi deistvitel'nosti [Everyday life and mythology: Studies on the semiotics of folklore reality]. St. Petersburg: Iskusstvo-SPB. (In Russian).

Connor, A. (2014). The crossword century: 100 years of witty wordplay, ingenious puzzles, and linguistic mischief. New York: Gotham Books.

Crossman, E. K., Crossman, S. M. (1983). The crossword puzzle as a teaching tool. Teaching of Psychology, 10(2), 98-99.

Davis, T. M., Shepherd, B., Zwiefelhofer, T. (2009). Reviewing for exams: Do crossword puzzles help in the success of student learning? The Journal of Effective Teaching, 9(3), 4-10. 
Dubin, B. (2010). Kniga — chtenie - biblioteka: Tendentsii nedavnikh let i problemy nyneshnego dnia [Book - reading - library: Tendencies of the last years and problems of the current day]. In B. Dubin. Klassika, posle i riadom: Sotsiologicheskie ocherki o literature i kul'ture [Classics, after and nearby: Sociological essays on literature and culture], 225-249. Moscow: Novoe literaturnoe obozrenie. (In Russian).

Dubin, B., Zorkaia, N. (2008). Chtenie i obshchestvo v Rossii 2000-kh godov [Reading and society of the 2000s]. Vestnik obshchestvennogo mneniia [The Russian Public Opinion Herald], 2008(6), 30-36. (In Russian).

Gudkov, L. D. (1994). Metafora i ratsional'nost'kak problema sotsial'noi epistemologii [Metaphor and rationality as a problem of social epistemology]. Moscow: RUSINA. (In Russian)

Hambrick, D. Z., Salthouse, T. A., Meinz, E. J. (1999). Predictors of crossword puzzle proficiency and moderators of age-cognition relations. Journal of Experimental Psychology: General, 128(2), 131-164.

Htwe, T. T., Sabaridah, I., Rajyaguru, K. M., Mazidah, A. M. (2012). Pathology crossword competition: an active and easy way of learning pathology in undergraduate medical education. Singapore Medical Journal, 53(2), 121-123.

Jaramillo, C. M. Z., Losada, B. M., Fekula, M. J. (2012). Designing and solving crossword puzzles: Examining efficacy in a classroom exercise. Developments in Business Simulation and Experiential Learning, 39, 213-222.

Lakoff, Dzh., Dzhonson, M. (2004). Metafory, kotorymi my zhivem [Trans. from Lakoff, G., Johnson, M. (1980). Metaphors we live by. Chicago; London: The Univ. of Chicago Press]. A. N. Baranov (Ed., Intro.). Moscow: URSS. (In Russian)

Saran, R., Kumar, S. (2015). Use of crossword puzzle as a teaching aid to facilitate active learning in dental materials. Indian Journal of Applied Research, 5(4), 456-457.

Scalco, M. Z., Reekum, R. (2006). Prevention of Alzheimer disease. Encouraging evidence. Canadian Family Physician. Medecin de famille canadien, 52, 200-207.

Scarmeas, N., Stern, Y. (2004). Cognitive reserve: Implications for diagnosis and prevention of Alzheimer's disease. Current Neurology and Neuroscience Reports, 4(5), 374-380.

Shevchenko, O. (2001). Krossvord. Lekarstvo ot skuki iz deviati bukv [Crossword. A cure for boredom in nine letters]. Neprikosnovennyi zapas [Debates on Politics and Culture], 2001(4). Retrieved from https://magazines.gorky.media/nz/2001/4/krossvord-lekarstvo-otskuki-iz-devyati-bukv.html. (In Russian).

Shevchenko, O. (2007). 'Wiggle your wits!' Social restructuring and the transformation of entertainment genres in today's Russia. Social Identities, 13(5), 577-595.

Shiffrin, R. M., Atkinson, R. C. (1969). Storage and retrieval processes in long-term memory. Psychological Review, 76(2), 179-193.

Skliarova, E. E. (2011). Ispol'zovanie priemov mediadidaktiki dlia aktivizatsii poznavatel'noi deiatel'nosti studentov [Using the methods of mediadidactics for activation of cognitive activity of students]. Problemy i perspektivy razvitiia obrazovaniia $v$ Rossii [Problems and perspectives of development of education in Russia], 12, 156-163. (In Russian).

Swift, O. (2007). The people's puzzle: Crossword and knowledge politics. London: Goldsmiths College. (Goldsmiths Anthropology Research Papers; No. 13).

Thanasuan, K. (2015). Using cognitive word games to promote lexical memory access (A dissertation submitted in partial fulfillment of the requirements for the degree of doctor of philosophy in Applied Cognitive Science and Human Factors, Michigan Technological University). Retrieved from https://pdfs.semanticscholar.org/3e62/d3bb36cdf85ef25ba3b16245dc8b44b38b0a.pdf. 
Verghese, J., Lipton, R. B., Katz, M. J., Hall, C. B., Derby, C. A., Kuslansky, G., Ambrose, A. F., Sliwinski, M., Buschke, H. (2003). Leisure activities and the risk of dementia in the elderly. The New England Journal of Medicine, 348(25), 2508-2516.

Volkova, M. V. (2011). Zagadka i krossvord kak tipy teksta: semanticheskii i pragmaticheskii aspekty [Riddles and crosswords as text types: semantic and pragmatic aspects] (Cand. Sci. (Philology) Theses, Smolensk State University). Smolensk. (In Russian)

Wilson, R. S., Bennett, D. A., Bienias, J. L., Aggarwal, N. T., Mendes De Leon, C. F., Morris, M. C., Schneider, J. A., Evans, D. A. (2002). Cognitive activity and incident AD in a population-based sample of older persons. Neurology, 59(12), 1910-1914.

Yudin, A. V. (2007). Russkaia narodnaia dukhovnaia kul tura: Uchebnoe posobie dlia studentov vuzov [Russian folk non-material culture: A handbook for students]. Moscow: Vysshaia shkola. (In Russian).

Zakharenko, I. V. (1998). Russkaia kognitivnaia baza i russkoe kul'turnoe prostranstvo v zerkale krossvordov [The Russian cognitive framework and Russian cultural space as reflected in crossword puzzles]. In V. V. Krasnykh, A. I. Izotov (Eds.). Iazyk, soznanie, kommunikatsiia: Sbornik statei [Language, mind and communication: Collection of articles] (Vol. 5), 32-40. Moscow: Filologiia. (In Russian).

$$
* * *
$$

\section{Информация об авторе}

\section{Елена Вивич}

бакалавр культурологии

студентка магистратуры,

факультет гуманитарных наук,

Национальный исследовательский

университет

«Высшая школа экономики»

Россия, 101000, Москва, ул. Мясниикая,

ग. 20

Тел.: + 7 (495) 772-95-90*12142

vevivich@edu.hse.ru

\section{Information about the author}

\section{Elena Vivich}

Bachelor of Cultural Studies

MA Student, Faculty of Humanities,

National Research University

Higher School of Economics

Russia, 101000, Moscow, Myasnitskaya Str. 20

Tel.: +7 (495) 772-95-90*12142

凶evivich@edu.hse.ru 